\title{
Effects of Jigsaw Model of Cooperative Learning on Self-Efficacy and Achievement in Chemistry among Concrete and Formal Reasoners in Colleges of Education in Nigeria
}

\author{
J. S. Mari and Sani Abdullahi Gumel
}

\begin{abstract}
The effect of cooperative learning strategy on students self-efficacy and achievement in chemistry at the College of education level in Nigeria have not been adequately investigated. This study therefore investigates such effect by comparing the academic achievement and self-efficacy of concrete and formal reasoners exposed to the strategy and those exposed to the traditional method. Two groups of students were randomly selected for the study. One group was exposed to the Jigsaw model of cooperative learning (experimental group) while the other group was exposed to the traditional method (Control group). Variables investigated were effect of the strategy on academic achievement and self-efficacy of formal and concrete reasoners. T-test statistic was used to analyse the data at $\boldsymbol{P} \leq \mathbf{0 . 0 5}$ level of significance. Result obtained revealed that: The use of cooperative learning strategy has significant effect on the academic achievement of formal 'reasoners' more than that of the concrete 'reasoners'. The difference is statistically significant. Difference in the effect of cooperative learning strategy between the self-efficacy of students at concrete operational stage and those at formal operational stage who were exposed to cooperative learning strategy was not statistically significant. This paper therefore recommends that chemistry teachers in colleges of education in Nigeria need to have a clear understanding of the reasoning pattern of their students to enable them tailor their teaching to meet the students' learning need.
\end{abstract}

Index Terms-Cooperative learning, self-efficacy, concrete reasoners, formal reasoners traditional method.

\section{INTRODUCTION}

One of the social characteristics of a learner is the belief he holds in his capability to accomplish a task or activity that affect his live. In other words, self-efficacy belief is very essential in guiding learner's personnel and academic accomplishments. [1], identified self-efficacy belief as one of the learner's emotional input behavior with which he enters the learning environment. [2], defined self-efficacy as people's beliefs about their capability to produce designated level of performance that exercise influence over events that affect their lives. [3] identified three (3) critical issues related to individuals' self-beliefs thus;

"That students' difficulties in basic academic skills are often directly related to their beliefs that they cannot read' write, handle numbers, or think well- that they cannot learneven when such things are not objectively true;

Manuscript received January 10, 2014; revised March 20, 2014.

J. S. Mari is with the Department of Science Education, Ahmadu Bello University, Zaria-Nigeria (e-mail: jsmarison@yahoo.com).

S. A. Gumel is with the Department of Integrated Science, College of Education, Gumel, Jigawa State, Nigeria (e-mail: Sangume188@yahoo.com).
That many students have difficulty in school not because they are incapable of performing successfully but because they are incapable of believing that they can perform successfully- they have learned to see themselves as incapable of handling academic work or to see in the work as irrelevant to their perceptual world; and

That many if not most academic crises are crises of confidence".

Classroom environment is characterized with students of varying pattern of thought. These differences occur due to variation in the individuals' information processing mechanism as proposed by [4]. Some children process information through logical operation with concrete object. Such children according to [5] are classified as concrete thinkers. Understanding of the concepts of seriation and classification also manifest in this children. Similarly, [5] identified some other children as formal thinkers. These set of children differs from the concrete reasoners in their ability to carry out operations among symbols and think in abstraction [6]. While teachers can do nothing to increase student's mental capacity, they can modify their instructional strategies to make concepts easier to comprehend. It is therefore pertinent for the science teacher to have an understanding of the levels and modes of reasoning of their students and adopt a strategy that will tailor these differences in the students' pattern of thought in order to promote effective learning.

A variety of teaching strategies have been advocated for use in science and mathematics classroom, ranging from teacher-centered approach to more students-centred ones [7]. One of such methods according to [8] is cooperative learning. The idea of cooperative learning according to [9], is based on the premise that an individual can only achieve his/her goals, if other members of the group with whom he/she is learning can equally attain their goals. However, [10] also reported that cooperative learning results in a greater effort for achievement, more positive interpersonal relationships and greater psychological health than competitive or individualistic learning. This study adopts Jigsaw model of cooperative learning to determine how the use of the strategy could affect the performance and self-efficacy of students at concrete and formal levels of thinking.

\section{THE JIGSAW MODEL}

This model according to [8] was developed by Elliot and was based on the idea that cooperation will develop each individual, and each individual can reach a goal only if all 
other individuals in the group reach their goals. In Jigsaw, students are assigned to six member teams to work on academic material that has been broken down into sections. For example, the concept of acid might be divided into meaning and types, physical properties, chemical properties and uses. Each team member reads his or her section. Next members of different teams who have studied the same sections meet in expert groups to discuss their sections. Then the students return to their teams and take turns teaching their teammates about their sections. Since the only way students can learn sections other than their own is to listen carefully to their teammates, they are motivated to support and show interest in one another's work. Elliot used cooperative learning specifically to bring children of different races and ability together.

Elliot according to [8] based the theory and practice of JIGSAW approach on social psychological research, mutual interest, coordinated efforts, trust and helpfulness amongst group members. Also academic performance was found to improve amongst ethnic-minority pupils. Socially, there was substantial development in inter-ethnic acceptance, concern and trust [8]. Group members also showed an increased ability in taking on other perspective in role taking and promoting social sensitivity. [8] proposed the following steps to be followed while adopting this model:

1) Divide students into 5- or 6-person jigsaw groups. The groups should be diverse in terms of gender, ethnicity, race, and ability.

2) Appoint one student from each group as the leader. Initially, this person should be the most mature student in the group.

3) Divide the day's lesson into 5-6 segments corresponding to the number of the groups.

4) Assign each student to learn one segment, making sure students have direct access only to their own segment.

5) Give students time to read over their segment at least twice and become familiar with it. There is no need for them to memorize it.

6) Form temporary "expert groups" by having one student from each jigsaw group join other students assigned to the same segment. Give students in these expert groups time to discuss the main points of their segment and to rehearse the presentations they will make to their jigsaw group.

7) Bring the students back into their jigsaw groups.

8) Ask each student to present her or his segment to the group. Encourage others in the group to ask questions for clarification.

9) Float from group to group, observing the process. If any group is having trouble (e.g., a member is dominating or disruptive), make an appropriate intervention. Eventually, it's best for the group leader to handle this task. Leaders can be trained by whispering an instruction on how to intervene, until the leader gets the hang of it.

10) Give quiz at the end of the session on the material learnt.

\section{METHODOLOGY}

\section{A. Research Design}

Pretest-posttest experimental control group design was used for the study. This involves two groups in which one group was assigned as experimental and the other control group. All the two groups were pre tested to determine their entry level. The two groups were found to be equivalent based on the result of the pretest.

\section{B. Population, Sample and Sampling Procedure}

The population of the study comprised of 200 level chemistry students of the 7 State Colleges of Education in the North-west geopolitical region.

Sa'adatu Rimi College of Education Kano, Isa Kaita College of Education Dutsamma, Jigawa State College of Education Gumel and Zamfara State College of Education Maru were randomly selected. These schools were pretested using Chemistry Achievement Test (CAT), Test of Logical Thinking (TOLT) and the General Self-efficacy Scale (GSE). This was done to identify the two schools that can be used as experimental and control groups. The mean scores of the four schools in the chemistry achievement test (CAT) were tested using t-test statistic to choose a pair of school that had no significant difference in their academic performance in the CAT. Isa Kaita College of Education Dutsamma and College of Education Gumel were found to have no significant difference and were therefore selected. College of Education Gumel was randomly assigned experimental and Isa Kaita College of Education Dutsamma control group. In each of these two schools, the intact class was used so that the school academic calendar is not tampered with.

The experimental group has a total population of 96 students, while the control group has a total of 84 . However, the performance of the subjects in the two schools in the test of logical thinking (TOLT) was used in classifying the subjects in to concrete and formal reasoners. Among the 96 subjects in the experimental group, 65 were found to be formal reasoners while 31 were found to be concrete reasoners. Similarly, in the control group 61 were found to be formal reasoners while 23 concrete reasoners.

\section{Instrumentation}

General Self-Efficacy Subscale (GSES), Chemistry Achievement Test (CAT) and Test of Logical Thinking (TOLT) were used for the pretest. The General Self-Efficacy Subscale (GSE) was adopted from [9] and it has a reported reliability coefficient of 0.86 . The GSE consists of 17 items assessing an individual's sense of general self-efficacy (e.g., "When I decide to do something, I go right to work on it"). Item responses was obtained using a 5-point Likert scale ranging from A (disagree strongly) to $\mathrm{E}$ (agree strongly). Total scores of general self-efficacy were obtained by summing the 17 items of the subscale. Higher total scores reflect greater general self-efficacy.

The chemistry achievement test (CAT) consists of 40 multiple-choice items selected from the moderated NCE final semester past question papers on the course unit selected for the study. The test items cover the entire course unit and are meant to determine academic achievement of the students.

The TOLT consists of 10 items and was adopted from [4]. It evaluates five reasoning abilities which have relevance to the teaching of science. It is a multiple-choice test that provides multiple justifications for the selected answer. The TOLT test contains two items from each of the following: 
proportional reasoning, probabilistic reasoning, controlling variable, co relational reasoning, and combinatorial reasoning. Items 1 and 2 measures proportional reasoning, items 3 and 4 measures control of variables, items 5 and 6 probabilistic reasoning, items 7 and 8 co relational reasoning, and combinational reasoning items 9 and 10. Students select a response from among five possibilities and then they are provided with five justifications among which they choose from. The correct answer is the correct choice plus the correct justification. Students' performance on TOLT was used as a measure of reasoning ability and was used in classifying the students in to concrete or formal reasoners.

The experimental group received treatment (the Jigsaw model of cooperative learning), while the control group was taught using the lecture method. The Test of Logical
Thinking (TOLT) was used in classifying the subjects into formal and concrete reasoners. After treatment, the two groups were post tested to determine the effects of treatment.

\section{Result and Discussion}

Only the academic achievement of students in formal and concrete reasoning levels who were exposed to the cooperative learning strategy is presented here. The hypothesis was tested with the two sample t-test. In Table 1, a summary of the test result is presented.

Hypothesis 1: There is no significant difference in the academic achievement of students at concrete operational stage and those at formal operational stage when exposed to cooperative learning strategy.

TABLE I: T-TEST ON ACADEMIC ACHIEVEMENT OF FORMAL AND CONCRETE 'REASONERS’ EXPOSED TO THE COOPERATIVE LEARNING STRATEGY

\begin{tabular}{llllllllll}
\hline Reasoning & $N$ & Mean & $\begin{array}{l}\text { Std. } \\
\text { Dev. }\end{array}$ & Std. Error & t-value & DF & $P$ & t-critical & Remark \\
\hline Formal & 65 & 28.85 & 3.224 & 0.413 & 4.614 & 81 & 0.000 & 2.00 & Sig. \\
Concrete & 31 & 24.59 & 4.847 & 1.033 & & & & & \\
\hline
\end{tabular}

TABLE II: T-TEST ON SELF-EFFICACY BY FORMAL AND CONCRETE 'REASONERS’ EXPOSED TO COOPERATIVE LEARNING STRATEGY

\begin{tabular}{llllllllll}
\hline Reasoning & $N$ & Mean & Std. Dev. & Std. Error & t-value & DF & P & t-critical & Remark \\
\hline Concrete & 31 & 3.37 & 0.463 & 0.083 & 1.434 & 94 & 0.155 & 2.00 & NS \\
Formal & 65 & 3.21 & 0.507 & 0.063 & & & & & \\
\hline
\end{tabular}

The test revealed that students who are formal 'reasoners' were significantly better in their academic achievement than students who were concrete 'reasoners' exposed to the use of cooperative learning strategy in the study. This is indicated in the table by an observed t-value of 4.614 as against 2.00 which stands for the critical value at the 81 degree of freedom. The observed significant level for the test is $0.000(P<0.05)$. The null hypothesis that there is no significant difference in the academic achievement of students at concrete operational stage and those at formal operational stage when exposed to cooperative learning strategy is therefore rejected. Students with formal reasoning were more enhanced in their academic achievement than those with concrete reasoning when exposed to the cooperative learning strategy.

Hypothesis 2: There is no significant difference in self-efficacy of students at concrete operational stage and those at formal operational stage when exposed to cooperative learning strategy.

The ratings of the students in the concrete and formal reasoning levels on the self-efficacy scale after their exposure to cooperative learning strategy were used for this test. Table II shows the summary of the test conducted with the two sample t-test procedure.

From the result in the table, the two groups did not differ significantly in their self-efficacy after their exposure to the cooperative learning strategy. The observed t-value (1.434) is lower than the critical value of 2.00 and the observed significant level for the test is $0.155(P>0.05)$. With these observations, the null hypothesis that there is no significant difference in self-efficacy of students at concrete operational stage and those at formal operational stage when exposed to cooperative learning strategy is therefore retained.

Hypothesis one tested for significant differences between the academic achievement scores of students at concrete operational stage and those at formal operational stage when exposed to cooperative learning strategy. The test revealed that the two groups were significantly different in their academic achievements in favor of formal reasoners. This null hypothesis was therefore rejected. From the mean scores it was observed that students in formal operational stage had higher academic performance than those in concrete operational stage when both were exposed to the cooperative learning strategy. This finding agrees with the report [4], who observed that difference between formal and concrete 'reasoners' was associated with the variation in the individuals' information processing mechanism as proposed by [5]. In the report it was opined that some children process information through logical operation with concrete object while others adopt the formal approach. The ability of students at formal operational stage to reason in abstraction is an added advantage they had over their counterparts who operates at concrete operational level and may be one of the factors responsible for the observed differences between the two groups.

Hypothesis two tested for significant difference between self-efficacy of students at concrete operational stage and those at formal operational stage when exposed to cooperative learning strategy. The result of the test did not reveal significant difference between the two groups of students involved in the study. The null hypothesis was therefore retained. This finding is in line with [11] who investigated the effect of group investigative method and Jigsaw method of cooperative learning strategy. The outcome of the investigation revealed that in both methods, learners achieve the skill of graphing and experimentation in post-test compared the pre-test but more students achieved the skill of observation in the pre-test. But strikingly, the subjects exposed to group investigative method achieved the same before and after exposure to this form of cooperative learning. 


\section{CONCLUSION}

From the findings of this investigation into the effects of cooperative learning strategy on self-efficacy belief and academic achievement of concrete and formal 'reasoners' in Colleges of Education in Nigeria, the following conclusion is drawn:

Cooperative learning strategy could be an alternative method of teaching chemistry in the colleges of Education because it has the capability of enhancing academic performance of formal and concrete reasoners' in chemistry

The strategy does not significantly affect the self-efficacy of formal and concrete reasoners as revealed by result of the study.

\section{RECOMMENDATIONS}

Based on the findings from the analyzed data, the researchers would want to recommend as follows:

1) Teachers of the colleges of education should as a matter of importance be alternating the teaching method they use for teaching the subject so as to improve students' understanding and performance.

2) It may be necessary to evaluate students' reasoning ability to know how grouping for cooperative learning strategy can be adopted such that every student would be able to benefit from it.

\section{REFERENCES}

[1] N. Boldaji. (2008). The relationship between learning style self-efficacy belief and academic fields in high school students. [Online]. Available: www.psychointeractive com.

[2] A. Bandura, "Self-efficacy," in V. S. Ramachaudran (Ed.), Encyclopedia of Human Behavior, vol. 4, pp. 71-81, New York: Academic Press, 1994.

[3] F. Pajares. (Nov. $15^{\text {th }}, 2009$ ). Self-efficacy belief in academic context: An $2002 . \quad$ outline Anline]. Available: http://des.emory.edu/mfp/efftalk.html.

[4] J. S. Mari, "The effect of process skills instruction on formal reasoning ability among senior secondary school students in Kaduna state 2001,' Nigeria.

[5] J. Piaget, "Intellectual evolution from adolescence to adulthood 1972," Human Development, vol. 5, pp. 1-12.

[6] C. W. Keys, "An interpretative study of students' use of scientific reasoning during a collaborative report writing intervention in ninth grades general science," Science Education, vol. 79, pp. 415-435, 1995.

[7] E. Zakaria and Z. Iksan, "Promoting cooperative learning in science and mathematics education: A Malaysian perspective," Eurasia Journal of Mathematics, Science and Technology Education, vol. 3, no. 1, pp. 35-39, 2007.

[8] S. B. Olorukooba, "The relative effects of cooperative instructional strategy and traditional method on the performance of senior secondary school chemistry students," Ph. D thesis, 2001.

[9] S. Joseph. (2004). Exploring the relationship between Self-ficacy beliefs and purpose in Life. PhD dissertation, University of Ohio. [Online]. Available: www.ohio.educ.com.

[10] D. W. Johnson and R. T. Johnson, "Cooperative learning and achievement," in S. Sharan (Ed.), Cooperative Learning 1999: Theory and Research, pp. 173-202, New York: Praeger.
[11] M. A. Rapudi. (2009). The effects two methods of cooperative learning on the development of learners Process skills. [Online]. Available: http://uir.unisa.ac.za/bitstream/handle/10500/1394/02chapteri.pdf.

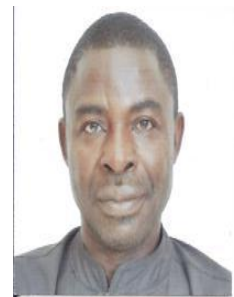

Jonathan Salihu Mari was born on 2nd January 1960 in an ancient and historical city called Nok-the popula Nok culture that appeared in Nigeria 1000BC. He holds BSc chemistry, MEd Science Education, and $\mathrm{PhD}$ Chemistry Education, from Ahmadu Bello University Zaria, Nigeria.

$\mathrm{He}$ is currently a professor of Science Education, Department of Science Education, Ahmadu Bello University Zaria. He has been lecturing and carrying out researches on effects of reasoning ability and learning of chemistry concepts and other related areas. He has also worked in Nasarawa State University, Keffi and Federal College of Education, Zaria. He was coordinator Diploma programmes, Post graduate coordinator, head of Department, coordinator, Programes Evaluation among others. He had Some publications. His research interests include reasoning and learning, acquisition of science process skills, effects of instructional strategies on learning, cognitive functioning, misconceptions in learning, gender-related differences in learning.

Professor Mari is a member of the following associations: Member, Nigerian Science Teacher Association Member, Nigerian Integrated Science Teacher Education Project Member, National Association of Researchers in Science Education, Member, UNESCO Team for promoting active learning, Member, Science Association of Nigeria, Member royal chemical society of Nigeria among others. Representative Faculty of Board of Science, Member, Committee on verification of Excess Workload ,Member, Committee on review of manuscripts, book of reading, Faculty of Education, ,Member, Committee on assessment of efficiency in academic record keeping and retrieval, Member, Chairman, Committee on renovation of laboratory, Service-com committee,r, university senate standing committee . He has published over 40 papers in reputable journal in Nigeria and Europe

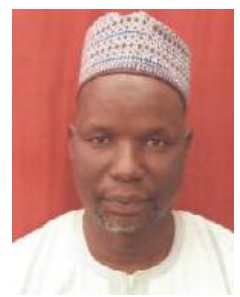

Sani Abdullahi Gumel was born in Gumel, Jigawa State Nigeria on 1st Jan. 1970. After his primary and secondary education, he attended Kano State College of Education Gumel where he obtained Nigeria certificate in education (NCE) in mathematics/chemistry. He also acquired a bachelor degree in chemistry education from Ahmadu Bello University (A.B.U) Zaria, Zaria Kaduna State Nigeria in 1995. Later he obtained a Master degree in science education from the same university in 2007.

He started working as a classroom secondary school mathematics teacher in 1992. Later in 1997 he joined Jigawa State Colege of Education as a lecturer. He holds several positions in the college which includes among others Head chemistry department and Dean students' affairs. The author had written a paper on "Developing entrepreneurial skill in the learner through chemistry education-A Nigeran" perspective (SEAMEO-RECSAM) international conference Oct. 2013 Penang-Malaysia. He also wrote several chapters in different books including one on "Appropriate technique for teaching Acid Base and Salt" in Science Teachers Association of Nigeria (STAN) book titled "Science Teachers Association of Nigeria (STAN) Series 3, Semadeen Printing Press.He undertook several researches on science method and is presently writing his $\mathrm{PhD}$ dissertation at A.B.U Zaria-Nigeria.

Mr Abdullahi is a member of Teachers Registration Council of Nigeria (TRCN) and an associate member of Science Teachers Association of Nigeria (STAN). He served as a member of the security committee of college of education Gumel, member committee of deans of the college, chairman students' disciplinary committee, member college management committee, member college academic board, member examination malpractice committee of the college and chairman college sports committee. 